\title{
Comparative Analysis of Different Flavonoids on the Immediate Shear Bond Strength of Bleached Enamel Surface: An ex-vivo Study
}

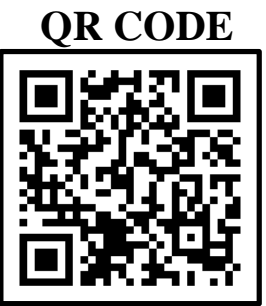

\section{NIDHI SHRIVASTAVA*1, MARISHA BHANDARI²}

INTRODUCTION: Bleaching, although considered as the first choice of treatment for discoloured teeth, can be utilized in conjunction with composite resin bonding or veneering and porcelain laminate veneers, to provide a more esthetic result.

AIM: The aim of the ex-vivo study is to obtain a comparative analysis to evaluate the effectiveness of antioxidants on the immediate composite bond strength on bleached enamel surface.

MATERIALS AND METHOD: Freshly extracted human permanent maxillary central incisors were selected and prepared for the respective study. All the specimens then were randomly divided into two control groups and three experimental groups, each group consisting of 20 specimens each. Among these were three experimental groups 10\% Sodium Ascorbate, 5\% Grape Seed extracts (Proanthocyanidin, PA) \& 10\% Green tea extracts (catechins and epigallocatechin gallate, CA and EG) and two control groups (Positive control \& Negative control).

RESULTS: When compared to Group 1 (positive control, $26.24 \pm 0.90 \mathrm{MPa}$ ), Group 3 (5\%Grape seed extract; $32.17 \pm 1.52 \mathrm{MPa}$ ), Group 4 (10\% Sodium Ascorbate; $28.91 \pm 1.50 \mathrm{MPa})$ and Group $5(5 \%$ Green tea extract; $24.10 \pm 1.21 \mathrm{MPa})$ showed significantly higher shear bond strength values.

CONCLUSION: The present study indicated that the shear bond strength of the antioxidant group (Group3) is higher than all three experimental groups. In addition, the shear bond strength of the bleached group (Group 2) is significantly lower than all the other groups. This implies that immediate use of antioxidants, contributes in reversal the bond strength of bleached enamel.

KEYWORDS: Bleaching Agents, Sodium Ascorbate, Grape Seed Extract, Enamel, Adhesive Polymerisation

\section{INTRODUCTION}

In the past, dentists were often dismayed by a patient's disappointment in a "Perfect Restoration" pain staking crafted of the finest gold or other restorative material with minimized enamel reduction and long-lasting preservation of function. Bleaching is one of the widely accepted esthetic treatments of $21^{\text {st }}$ century. The earliest evidence of using tooth bleaching to achieve desired esthetic appearance clinically took place more than two centuries ago, where bleaching agents were directly painted onto the tooth surface (labial) or placed just $2 \mathrm{~mm}$ above cemento-enamel junction inside root canal treated tooth. ${ }^{1}$ Vital bleaching has been a viable and effective treatment to discoloured teeth, meeting the esthetic and conservative philosophy of contemporary dentistry.

The bleaching outcomes, however, are not predictable and although it should be considered as the first choice of treatment for discoloured teeth, sometimes it can be utilized in conjunction with composite resin bonding or veneering and porcelain laminate veneers, to provide a more esthetic result. ${ }^{2}$ Different types of bleaching agents are available from $10-35 \%$ hydrogen peroxide, $10-35 \%$ Carbamide Peroxide or commercial available bleaching kits, paint on brushes, dentifrices tooth paste, for in-office power bleaching, waiting room bleaching and at home bleaching, are constantly evolving and the effects of these new whitening systems on enamel bond strengths have not been thoroughly studied. 3 Despite having many advantages every bleaching agent also has some disadvantages. Paramount complication of using bleaching agents, is decreased composite resin bond energy to immediately etched enamel. ${ }^{4}$ It has also been reported that the weakening of bond occurrs both superficially and internally. The reduced bond strength could be attributed to the presence of residual oxygen that can adversely affect the adhesive polymerization. ${ }^{5}$ Studies have revealed that the reduced bond strength can be reversed by the use of antioxidants such as $10 \%$ Sodium Ascorbate, Ascorbic Acid, Butyl-Hydroxianisole, Catalase, Ethanol, Acetone, Gluthione Peroxide, Alphatocopherol, Sodium Bicarbonate, Grape Seed Extract (PA) and Green Tea Extract (catechins and epigallocatechin gallate). ${ }^{6}$ The purpose of this ex-vivo study was to obtain a comparative analysis to evaluate the effectiveness of antioxidants on the immediate composite bond strength on bleached enamel surface.

\section{MATERIALS AND METHOD}

Hundred freshly extracted human maxillary central incisors were included in the present studyafter 
collecting the informed consent and stored in deionized water, at $4^{\circ} \mathrm{C}$ for 6 months. All the collected teeth were examined under light microscope (Stemi 2000C - Carl Zeiss, Jena, Germany) to evaluate undesirable defects or cracks.

Specimen Preparation: The buccal enamel surface of each specimen was polished with wet 70o-grit silicon carbide abrasive paper on a polishing machine, to create a flat enamel surface. Each specimen was embedded $1 \mathrm{~mm}$ below the cemento-enamel junction. in self curing acrylic resin, using silicon mould that was $2.5 \mathrm{~cm}$ high, $2 \mathrm{~cm}$ diameter.

Artificial Saliva Immersion: All the specimens were immersed in $250 \mathrm{~mL}$ of artificial saliva solution at $37^{\circ} \mathrm{C}$ for 7 days, which were changed twice daily during this period. The artificial saliva was prepared from 1 gram sodium carboxymethyl cellulose, 4.3 gram Xylitol, 0.1 gram potassium chloride, $5 \mathrm{mg}$ calcium chloride, $40 \mathrm{mg}$ potassium phosphate, $1 \mathrm{mg}$ potassium thiocyanate and 100 distilled deionized water at $\mathrm{pH} 7$. After that the specimens were washed with water thoroughly for 30 seconds.

Group Division: These specimens were randomly assigned into five groups, among these were three experimental groups 10\% Sodium Ascorbate, 5\% Grape seed extracts \& $5 \%$ green tea extracts and two control groups [(Positive control \& Negative control), table 1].

\section{BLEACHING PROCEDURE}

All the groups (except group 1: positive control group) were bleached using carbamide peroxide $(30 \%$, Opalescence PF, India), according to manufacturer's instructions. Then all specimens were rigorously rinsed with water for 30 seconds, air dried and stored in artificial saliva.

\section{ANTIOXIDANT REQUISITION}

Group 1 (Positive Control): No bleaching. Sample stored in artificial saliva for 7 days.

Group 2 (Negative Control): 30\% carbamide peroxide bleaching + immediate restorative procedures.

Group 3: Immediately after bleaching procedure, 5\% proanthocyanidin was applied with applicator brush for 10 minutes. $5 \%$ proanthocyanidin (Vista Nutrition, Medizen Labs, India) was prepared by dissolving, $5 \mathrm{~g}$ of Grape Seed extract capsule in $100 \mathrm{ml}$ of sterile water.

Group 4: Immediately after bleaching procedure, $10 \%$ sodium ascorbate was applied with applicator brush for 10 minutes. $10 \%$ sodium ascorbate gel (Leo chemicals Private Limited, Bangalore, India) was prepared by diffusing carbopol in $100 \mathrm{ml}$ sterile water, with addition of ascorbic acid and sodium hydroxide.

Group 5: Immediately after bleaching procedure, 5\% catechins and epigallocatechin gallate was applied with applicator brush for 10 minutes. 5\% green tea solution was prepared by dissolving a $5 \mathrm{mg}$ catechins and epigallocatechin gallate extract pill (Camgreen, Giah Essence, Iran) into $100 \mathrm{ml}$ sterile water at the room temperature.

After 10 minutes, each specimen was thoroughly rinsed and dried using blotting paper. All specimens were subsequently stored in artificial saliva.

\section{RESTORATIVE PROCEDURES}

Acid etching was carried out, according to manufacturer's instruction (35\% Etchant, 3M ESPE Scotch Bond, USA), all were thoroughly washed and paper dried.

A total bond adhesive (3M ESPE ADPER Single Bond 2, USA) was used, according to manufacturer's instructions and was gently air thinned followed by light curing (Blue Phase $\mathrm{C}_{5}$, Ivoclar Vivadent, Ltd, 12

\begin{tabular}{|c|c|c|}
\hline GROUPS & SAMPLE SIZE (N) & PROCEDURE DESCRIPTION \\
\hline Group 1 (Positive control) & 20 & No bleaching +7 days delay for restorative procedures \\
\hline Group 2 (Negative control) & 20 & $\begin{array}{l}\text { 30\% Carbamide Peroxide Bleaching + immediate } \\
\text { restorative procedures }\end{array}$ \\
\hline $\begin{array}{c}\text { Group } 3 \text { (5\% Grape seed extract; PA } \\
\text { agent) }\end{array}$ & 20 & $\begin{array}{l}\text { 30\% Carbamide Peroxide Bleaching }+5 \% \text { Grape seed } \\
\text { extract }+ \text { immediate restorative procedures }\end{array}$ \\
\hline Group 4 (10\% Sodium ascorbate) & 20 & $\begin{array}{l}\text { 30\% Carbamide Peroxide Bleaching }+10 \% \text { Sodium } \\
\text { Ascorbate }+ \text { immediate restorative procedures }\end{array}$ \\
\hline $\begin{array}{c}\text { Group } 5 \text { (5\% Green tea extract; CA and } \\
\text { EG agent) }\end{array}$ & 20 & $\begin{array}{l}\text { 30\% Carbamide Peroxide Bleaching }+5 \% \text { Green tea } \\
\text { extract }+ \text { immediate restorative procedures }\end{array}$ \\
\hline
\end{tabular}

Table 1. Group division of the specimens 
omega St. Albany) for 10 seconds. Plastic tube of $4 \mathrm{~mm}$ height and $3 \mathrm{~mm}$ diameter was used as cylindrical stencil, which were compacted with composite resin (Filtek Z350 XT composite syringe, 3 M ESPE, USA) and then light cured (in all directions) for 40 seconds. All the specimens were stored in automatic thermocycler (KARA 10oo, Tehran, Iran) for 24 hours.

\section{SHEAR BOND STRENGTH}

All the groups were tested in Instron Universal Testing Machine with chisel model (fixture) lying perpendicular to the composite cylinder. Force was applied at a crosshead speed of $1 \mathrm{~mm} / \mathrm{min}$ until the cylinders got completely fractured from enamel surface. The collected results were statistically analyzed.

\section{RESULTS}

It was observed that the shear bond strength in group 1 $(26.24 \pm 0.90 \mathrm{MPa})$ was notably higher than group 2 $(18.34 \pm 1.24 \mathrm{MPa})$. In comparison with group 1 ( 26.24 $\pm 0.90 \mathrm{MPa})$, Group $3(32.17 \pm 1.52 \mathrm{MPa})$, group $4(10 \%$ $28.91 \pm 1.50 \mathrm{MPa})$ and group $5(24.10 \pm 1.21 \mathrm{MPa})$ showed significantly higher shear bond strength.

When compared, group $1(26.24 \pm 0.90 \mathrm{MPa})$ and group $3(32.17 \pm 1.50 \mathrm{MPa})$ exhibited almost similar values.

Between experimental groups, group $2(18.34 \pm 1.24$ $\mathrm{MPa}$ ) showed lowest mean values compared to other groups. Group $3(32.17 \pm 1.52 \mathrm{MPa})$ showed significantly higher values than Group $4(28.91 \pm 1.51 \mathrm{MPa})$ followed by group $5(24.10 \pm 1.21 \mathrm{MPa})$ and is shown in table 2 .

\begin{tabular}{|c|c|c|}
\hline GROUP & $\begin{array}{c}\text { MEAN } \pm \\
\text { STANDARD } \\
\text { DEVIATION }\end{array}$ & RANGE \\
\hline Group 1 & $26.24 \pm 0.90 \mathrm{MPa}$ & $\mathbf{2 9 . 0 7 - 3 0 . 9 7}$ \\
\hline Group 2 & $18.34 \pm 1.24 \mathrm{MPa}$ & $16.36-21.80$ \\
\hline Group 3 & $32.17 \pm 1.52 \mathrm{MPa}$ & $\mathbf{2 7 . 0 1 - 3 4 . 3 2}$ \\
\hline Group 4 & $28.91 \pm 1.50 \mathrm{MPa}$ & $\mathbf{2 5} \cdot 36-34.48$ \\
\hline Group 5 & $24.10 \pm 1.21 \mathrm{MPa}$ & $20.67-25.89$ \\
\hline
\end{tabular}

Table 2. Comparison of Mean Bond Strength Among all the Groups

\section{DISCUSSION}

Literature extensively shows that bleaching has an adverse effect on the immediate bond strength of bleached surface. ${ }^{7}$ This is due to presence of free oxygen radicals, which inhibits resin polymerization cure due to presence of free radical. If the oxygen rich layer is eradicated, the resin - tooth bond strength is reversed. The exact thickness of oxygen rich layer is not stated. Therefore, it should be > 5-10 $\mathrm{mm}$; otherwise, etching would have proved effective. ${ }^{8}$

The present study showed that value of group $1(26.24 \pm$ $0.90 \mathrm{MPa})$ is remarkably greater than that of Group 2 $(18.34 \pm 1.24 \mathrm{MPa})$. These findings are in accordance with the studies performed by various authors such as Titley et al., ${ }^{9}$, Stokes et al., ${ }^{10}$ and Miles et al. ${ }^{11}$

The results of our study showed that value of group 4 (28.91 $\pm 1.51 \mathrm{MPa}$ ) was notable higher than that of Group $2(18.34 \pm 1.24 \mathrm{MPa})$. Alike observations were described by Torres et al., ${ }^{12}$ they concluded that higher bond values were achieved using $10 \%$ sodium ascorbate on bleached tooth surface but lower when compared to unbleached tooth surface. Kimyai et al., ${ }^{13}$ reported higher bond value of teeth treated with $10 \%$ sodium ascorbate for 10 minutes, then immediately bleached tooth surface.

In the literary work, $10 \%$ sodium L- Ascorbate is proven to be favorable antioxidant agent for reversal of reduced strength of instantly bleached enamel, but there are deficient studies using 5\% 84929-27-1 Grape seed and $5 \%$ green tea extract as viable alternative. Hence in the present study, emphasis was placed on immediate use of 5\% 84929-27-1 grape seed and 5\% green tea extract as a potent antioxidant (for 10 minutes) on bleached enamel.

Berger et al., reported that green tea extract was used immediately after bleaching for $60 \mathrm{~min}$, the bond strength values were higher than control group (only bleached). ${ }^{14}$ The green tea catechins, such as EGCG and EGC, have potent antioxidant activities caused by the three adjacent $\mathrm{OH}$ groups in ECG and EC. Thus, green tea catechins were shown to possess potent antioxidant activity that is significantly higher. It is also stated that EGCG can be the main component responsible for capture of free radicals from the bleaching. ${ }^{15}$

This study shows that the treatment with 5\% 84929-271 grape seed (group 3) increases bond values remarkably, when compared to other groups.

This could be ascribed to the following:

1. Specificity of superoxide free radicals.

2. Presence of assorted donor sites on superoxide that traps oxygen free radicals.

3. The acid esterification of catechin by trihydroxy benzoic acid in superoxide, which magnifies the diradical forage ability. ${ }^{16-18}$ 
This study shows that, the bond value of group $3(32.17$ $\pm 1.52 \mathrm{MPa}$ ) is higher than other investigational groups. Furthermore, group $2(18.34 \pm 1.24 \mathrm{MPa})$ value was notably lower than other investigational groups. This suggested that immediate use of antioxidant imparts remarkably high bond value to bleached enamel.

\section{CONCLUSION}

Within the limitation of this ex-vivo study, the following conclusions were drawn;

1. Bleached tooth surface reduces shear bond value.

2. Immediate antioxidants administration for 10 minutes imparts notably higher bond strength.

3. Amid the flavonoids tested in the research, group 3 was most successful in overturning the immediate shear bond strength after bleaching.

\section{REFERENCES}

1. Manoharan M, Shashibhushan KK, Poornima P, Nik SN, Patil D, Shruthi AS. Effect of newer antioxidants on the bond strength of composite on bleached enamel. J Indian Soc Pedod Prev Dent. 2016;34:391-6. https://doi.org/10.4103/o970-4388.191430

2. Heymann HO. Additional conservative esthetic procedures. In: Roberson TM, Haymann HO, Swifth EJ. Sturdevent's Art and Science of Operative dentistry. $5^{\text {th }}$ ed. Noida: Reed Elsevier India Private Limited;2009. P. 625-41.

3. Dabas D, Patil AC, Uppin VM. Evaluation of the effect of concentration and duration of application of sodium ascorbate hydrogel on the bond strength of composite resin to bleached enamel. J Conserv Dent. 2011;14:356-6o.

4. Basting RT, Rodrigues JA, Serra MC, Pimenta LA. Shear bond strength of enamel treated with seven carbamide peroxide bleaching agents. J Esthet Restor Dent. 2004;16:250-9.

5. Oskoee PA, Navimipour EJ, Oskoee SS, Moosavi N. Effect of $10 \%$ sodium ascorbate on bleached bovine enamel surface morphology and microhardness. Open Dent J. 2010;4:207-10. https://doi.org/10.2174/1874210601004010207

6. Garcia EJ, Oldoni TL, Alencar SM, Reis A, Loguercio $\mathrm{AD}$, Grande RH. Antioxidant activity by DPPH assay of potential solutions to be applied on the bleached teeth. Braz Dent J. 2012;23:22-7. https://doi.org/10.159o/s010364402012000100004
7. Crim GA. Post-operative bleaching: effect on microleakage. Am J Dent 1992;5:109-12.

8. Cvitko E, Denehy GE, Swift EJ Jr., Ambrose WW, Lopes M. ultra-morphological study of interaction of dental adhesives with carbamide peroxide-bleached enamel.AM J Dent. 1998;11:291-301.

9. Titley KC, Torneck CD, Smith DC, Adibfar A. Adhesion of composite resin to bleached and unbleached bovine enamel. J Dent Res. 1998;67:1523-8. 10. Stokes AN, Hood JA, Dhariwal D, Patel K. effect of peroxide bleaches on resin enamel bonds. Quintessence Int. 1992;23:769-71.

11. Miles PG, Pontier JP, Bahiraei D, Close J. the effect of carbamide peroxide bleach on the tensile bond strength of ceramic brackets: an in vitro study. Am J Orthod Dentofacial Orthop. 1994;106:371-5. https://doi.org/10.1016/So889-5406(94)70058-3

12. Torres CRG, Koga AF, Borges AB. The effects of antioxidant agents as neutralizers of bleaching agents on enamel bond strength. Braz Dent J. 2006;5:971-76. https://doi.org/10.20396/bjos.v5i16.8641877

13. Kimyai S, Oskoee SS, Rafighi A, Valizadeh H, Ajami AA, Helali ZN. Comparision of the effect of hydrogel and solution forms of sodium ascorbate on orthodontic bracket-enamel shear bond strength immediately after bleaching: an in vitro study. Indian J Dent Res. 2010;21:54-8.

14. Berger SB, De Souza Carreira RP, Guiraldo RD, Lopes MB, Pavan S, Giannini M, et al. Can green tea be used to reverse compromised bond strength after bleaching? Eur J Oral Sci. 2013;121(4):377-81. https://doi.org/10.1111/eos.12062

15. Magalhaes AC, Wiegand A, Rios D, Hannas A, Attin T, Buzalaf MA. Chlorhexidine and green tea extract reduce dentin erosion and abrasion in situ. J Dent. 2009;37:994-8. 10.1016/j.jdent.2009.08.007

16. Spyrides GM, Perdigao J, Pagani C, Araujo MA, Spyrides SM. Effect of whitening agents on dentin bonding. J Esthet Dent. 2000;12:264-70.

17. Hattab FN, Qudeimat MA, al-Rimawi HS. Dental discoloration: an overview. J Esthet Dent. 1999;11:291310.

18. Carr AC, Tijerina T, Frei B. Vitamin C protects against and reverses specific hypochlorous acid and chloramine-dependent modifications of low density lipoprotein. Biochem J. 2000;346(pt 2):491-9. 
Cite this article as:

Shrivastava N, Bhandari M. Comparative Analysis of Different Flavonoids on the Immediate Shear Bond Strength of Bleached Enamel Surface: An ex-vivo Study. Int Healthc Res J. 2021;5(3)OR1-OR5. https://doi.org/10.26440/IHRJ/0503.06428

AUTHOR AFFILIATIONS: (*Corresponding Author)

1. Associate Professor, Department of Dentistry, Mayo Institute of Medical Sciences, Barabanki, India

2. Reader, Department of Conservative Dentistry and Endodontics, Seema Dental College and Hospital, Rishikesh, India

Source of support: Nil, Conflict of interest: None declared

Contact corresponding author at: nidhiendodontist[at]gmail[dot]com 